\title{
THERAPEUTIC JURISPRUDENCE AND PROCEDURAL JUSTICE IN SCOTTISH DRUG COURTS
}

The United Kingdom, in common with other western jurisdictions, has in recent years sought to develop more effective ways of responding to drug related crime. Although the link between drug use and crime is complex, it is recognised that much acquisitive crime in the UK occurs through the need for individuals with drug problems to obtain the financial resources necessary to maintain a regular supply of drugs. Previous legislative endeavours had focused primarily upon attempting to reduce the supply of illicit substances through increasingly severe sanctions for those convicted of drug dealing. However, by the late 1990s policy attention shifted towards demand reduction through the provision of drug treatment to individuals whose offending was related to the misuse of drugs. The rationale was that addressing drug misuse would, in turn, result in reduced levels of crime, since individuals would no longer need to commit offences to support their drug habits. The criminal justice system was perceived as a suitable route into treatment for individuals with drug problems in view of emerging research findings that indicated that mandated treatment could be as effective as treatment accessed voluntarily (Hough, 1996 and, more recently, McSweeney et al, 2006, 2007). Furthermore, evidence was emerging from the United States that Drug Courts, first introduced in 1989 and subsequently established across the country, were showing promise in reducing problematic drug use and drug-related crime (Belenko, 1998). 
Although courts in the UK already had the option of requiring offenders to seek treatment for their drug problems as a condition of probation, in practice there were often lengthy waiting lists. Unable to access treatment at the start of their orders, probationers were likely to continue offending, to breach their orders and to face a custodial sentence as a consequence. Through the 1998 Crime and Disorder Act, provision was made for the introduction of Drug Treatment and Testing Orders (DTTOs) across the UK. DTTOs, which drew upon the US Drug Court model, differed from existing community penalties in a number of important respects. First, they allowed for the regular drug testing of offenders as a requirement of the court. Second, they emphasised the case management role of the supervising officer, who would be responsible for co-ordinating service provision rather than directly providing services. Third, and perhaps most significantly, they included provision for sentencers to take an active role in reviewing the progress of offenders on orders by bringing them back to court on a regular basis (or, alternatively, scrutinising progress through paper-based reviews).

Pilot DTTO schemes were introduced in England in 1998 in three pilot sites, with varying degrees of success (Turnbull et al., 2000). Revocation rates differed markedly from 28 per cent in one site to 60 per cent in another and a number of issues were identified that needed to be addressed prior to any national rollout of orders. A subsequent analysis of recidivism found that two-year reconviction rates were high, with 80 per cent reconvicted and the reconviction rate varying significantly across schemes (Hough et al., 2003). The reconviction rate among those who completed their orders was 53 per cent compared with 91 per cent among those whose orders were 
revoked, suggesting that retention of offenders on orders was critical. Completers had significantly lower conviction rates in the two years after being given a DTTO than in any of the five years before.

Although formally part of the UK, Scotland has had a devolved parliament since 1999 and the criminal justice is the responsibility of the Scottish Government. While Scotland has historically had its own judicial system and separate legislation, some criminal justice legislation enacted in Westminster - including provisions for the introduction of DTTOs - has UK-wide jurisdiction. The first pilot DTTO scheme in Scotland was introduced in Glasgow in 1999, followed by a second pilot site in Fife in 2000. The choice of pilot sites was important because it allowed for a comparison to be made of the operation of DTTOs in both city and semi-rural locations. An initial evaluation of the Scottish pilots, focused upon their first 12 months of operation, found that the schemes had been successful in reducing drug use and associated offending in the short term, with weekly self-reported expenditure on drugs falling from an average of $£ 490$ per week immediately prior to an order to $£ 57$ per week after six months (Eley et. al, 2002) ${ }^{1}$. DTTOs were subsequently rolled out to other parts of Scotland and are now available nationally.

Although representing an innovative criminal justice response to drug-related offending, DTTOs were open to criticism. In particular, Bean (2002) described them as 'watered down' versions of Drug Courts insofar as they contained some of their elements but did not allow for the development of the co-ordinated multi-professional team approach which characterises Drug Courts in other jurisdictions. Alert to the shortcomings of DTTOs and following a review of international developments in 
Drug Courts (Walker, 2001), the Scottish Executive decided to build upon the experience of the DTTO pilot sites by introducing pilot Drug Courts in Glasgow and Fife $^{2}$. The Glasgow Drug Court became operational in November 2001 and the Fife Drug Court made its first orders in September 2002. The Scottish Executive's interest in problem solving courts was extended in 2004 with the introduction of a pilot Domestic Abuse Court in Glasgow in 2004 that, like the Drug Courts, was subject to independent evaluation (Reid-Howie Associates, 2007). Pilot Drug Courts were subsequently introduced in England and Wales, where a process evaluation of the pilots in London and Leeds (Matrix Knowledge Group, 2008) preceded an announcement by the Secretary of State for Justice in March 2008 that further Drug Court pilots would be introduced.

\section{Key features of the Scottish Drug Courts}

The pilot Drug Courts that were established in Scotland shared many features in common with similar courts in other jurisdictions. As Gelebein (2000) has indicated, these include: integration of substance misuse treatment with criminal justice processing; the use of a non-adversarial approach; early identification of eligible participants and rapid access to treatment; access to a range of treatment, rehabilitation and related services; frequent testing for the use of illicit drugs; a coordinated approach by sentencers, prosecution, defence and treatment providers to secure compliance by participants; ongoing judicial review of participants' progress; partnerships with other relevant agencies to provide ongoing support for participants; and integral monitoring and evaluation. 
There were, however, some important differences. Unlike in many of the US Drug courts, it was agreed from the outset that the Scottish Drug Courts would be aimed at repeat offenders whose offending was assessed as being directly related to their dependence on or propensity to use drugs and who were at immediate risk of receiving a custodial sentence. The Drug Courts were therefore located within the Sheriff Summary Courts - the middle level court with sentencing powers of up to 6 months imprisonment for individual offences.

The sentencing options available to the Drug Courts were the same as those available to any Sheriff Court operating under summary proceedings. However, given the problem solving focus of the Drug Courts, it was anticipated that sentences imposed would include DTTOs, probation orders (with or without additional requirements) and deferred sentences. In practice, the majority of orders made in the Drug Courts in the first two years of the pilot were DTTOs (78 per cent of cases in both Glasgow and Fife). Probation orders were likely to be imposed where the offender was identified as having additional problems that required intervention and support beyond that available through a DTTO or where the Sheriff wished to bring the offender back for review on more than a monthly basis ${ }^{3}$. Deferred sentences were generally employed in respect of additional or further offences to provide the Drug Courts with an incentive for good progress ${ }^{4}$ or, equally, a sanction if offenders were not responding well ${ }^{5}$.

Sentences were imposed in the Drug Courts following a deferment of one month, on bail $^{6}$, for assessments by the Supervision and Treatment Teams. If a Drug Court order was recommended by the team and the court agreed with the recommendation, an 
order would be imposed for between 6 months and three years ${ }^{7}$, during which time offenders would be linked into a treatment service (usually methadone), seen regularly by their supervising social worker and addiction worker, subjected to regular drug testing (typically three times per week in the early stages of the order) and brought back to court regularly (at least once a month and often twice a month) to have their progress reviewed by the Drug Court Sheriff. Subject to progress, offenders could have specific requirements of their orders amended, such as the frequency of testing and reviews increased or decreased.

A central tenet of the Drug Courts was the recognition that drug misuse is a relapsing condition and for this reason concerted efforts were made to retain offenders on their orders. In the event of non-compliance the court could impose sanctions, such as varying the frequency of reporting and/or testing. When the Drug Courts were initially introduced, there were no legislated sanctions available to deal with more serious or persitent non-compliance, other than to terminate the order and impose an alternative (usually custodial) sentence. Since July 2003, however, the Drug Courts have had the power to impose short prison sentences (of up to 31 days cumulatively) or short periods of community service while allowing the Drug Court order to continue. If good progress was made on an order (as indicated by negative drug tests and co-operation with other requirements) it would run to the termination date or could be discharged early if a stage was reached where no further progress was deemed to be required.

While both Drug Courts operated broadly in this way, there were important organisational and operational differences across the two pilot sites. In Glasgow, the 
Drug Court team comprised two Sheriffs who sat in the court on alternative weeks ${ }^{8}$, a dedicated Procurator Fiscal (prosecutor), a dedicated clerk and court officer and the Drug Court Supervision and Treatment Team. The latter consisted of a team leader, supervising social workers, addiction workers, treatment providers and medical staff who were located together in shared premises. A Drug Court Co-ordinator - who was seconded from the Procurator Fiscal Service - facilitated the work of the Drug Court team.

Glasgow Sheriff Court is the largest court of its level in Europe and it was not considered feasible for the Drug Court to deal with the anticipated volume of cases that might be referred to it. Instead, the Drug Court when initially established and for the first two years of its operation targeted accused persons who had been detained in police custody and who were prepared to tender a guilty plea in respect of the offences with which they had been charged. This process was intended to ensure that offenders could be 'fast tracked' into treatment services. The other Sheriffs in Glasgow retained the capacity to make DTTOs in respect of offenders who came into the court system through other routes. Two hundred and seventy-one cases were referred for a Drug Court assessment during the first two years of the Glasgow pilot (McIvor et al., 2006).

In Fife the Drug Court was presided over by one Sheriff (with backup) who sat in one court for two days per week and in a second court for one day per week. A designated Sheriff Clerk provided the appropriate administrative support in each court. The Drug Court Supervision and Treatment consisted of a team leader, social workers and assistants, addiction workers, medical officers, ten nurses and two project workers 
from a local Drug and Alcohol Project. The Supervision and Treatment Team was organised into three multi-professional sub-teams which covered different parts of the geographical area served by the Drug Court. Unlike in Glasgow, there was no dedicated prosecutor and no Drug Court co-ordinator in Fife.

All potential Drug Court cases in Fife were identified by Sheriffs presiding over other summary courts in the county (sometimes brought to their attention by defence agents or, less usually, social workers). Offenders were referred across to the Drug Court at the sentencing stage if the adjudicating Sheriff thought that a Drug Court disposal might be appropriate. Sheriffs in Fife had agreed that from its inception only the Drug Court would impose DTTOs and all existing DTTOs were transferred in to the Drug Court when it became operational in September 2002. However, it should be noted that the majority of cases in Fife (as in Glasgow) were still dealt with in the Sheriff Summary Courts: in 2003, for example, 5,542 persons had a charge proved in Fife Sheriff Summary Courts (Scottish Executive, 2005) while in the first two years of operation 872 referrals were made to the Drug Court, involving 382 offenders (McIvor et al., 2006).

\section{Methods}

The evaluation of the Drug Court pilots was aimed at establishing whether they were being successful in reducing drug misuse and related offending, whether they were cost-effective and whether the procedures that had been instituted were operating well (McIvor et al., 2006). This article focuses on one particular aspect of the Drug Courts' operation: the involvement of Sheriffs in overseeing the progress of offenders made 
subject to orders. It draws upon interviews with Sheriffs, other professionals and drug court participants and on observation of the Drug Courts in operation, to highlight the central role of the Drug Court Sheriffs as motivators, sanctioners and enforcers and, utilising Tyler's (1991) work on procedural justice and legitimacy, to consider how in this capacity the Drug Court Sheriffs appeared to have played an important part in assisting drug-misusing offenders to lead law-abiding lives.

The data presented in this article were derived from two primary sources: interviews (with Drug Court participants and professionals) and observation of court processes. Across the two Drug Courts, 143 semi-structured interviews were conducted with Drug Court participants at various stages of their orders (including, in Glasgow, with a sample whose orders had been breached). The majority of interviews (136) were conducted with men (reflecting the over-representation of men on Drug Court Orders especially in Glasgow) and the very low number of women interviewed prevented any analysis of responses by gender.

Semi-structured interviews were also conducted with five Drug Court Sheriffs, with two 'back-up' Sheriffs (in Fife) and with members of the Drug Court teams. The latter included social workers, addiction workers, nurse and medical officers and, in Glasgow, the Drug Court Co-ordinator and Procurator Fiscal. The majority of professional respondents were interviewed on two occasions: once towards the first six months of the Court's operation and again towards the end of the first two years, to capture any changing perspectives on the Drug Courts' operation over time. This resulted in a total of 68 professional interviews in Glasgow and 66 in Fife. In Glasgow, further interviews were conducted with one of the original Sheriffs and with 
the two replacement Sheriffs in the Court's third year of operation, during which some revised procedures has been introduced. Interview data were coded and analysed thematically.

Systematic observation was undertaken of both Drug Courts in action. These observations focused upon pre-review meetings at which the progress of individual cases was discussed in private by members of the Drug Court team and court-based review hearings at which participants' progress was discussed in open court. Observation took place across the first two years' operation of each court, with participants' cases being observed at different stages of their orders. Eighty-eight prereview meetings in Glasgow and 29 in Fife were observed were observed along with 228 review hearings in Glasgow and 203 in Fife. Given the low numbers of women on Drug Court Orders, the majority of observations involved men. An observation pro-forma was used to record the processes observed. Information recorded included details of those present, the duration of the interaction and the nature and content of dialogue between the different parties concerned. Quantitative data were analysed using SPSS while qualitative data were subjected to thematic coding and analysis.

\section{Judicial involvement in the Drug Court process}

There is growing evidence from across a number of jurisdictions that participation in Drug Courts can contribute to reductions in drug use and drug-related offending and improvements in health and well-being (e.g. Belenko, 2001; Freeman, 2002; Gebelein, 2000; Goldkamp, 2000; Goldkamp et al., 2001; Indermauer et al., 2004; Lind et al., 2002; Makkai and Veraar, 2003; Wilson et al., 2004). However, given the 
multi-faceted nature of Drug Court programmes, there is also growing interest in which features of Drug Courts are associated with success. Through his analysis of the operation of two US drug Courts (Portland, Oregon and Las Vegas, Nevada) over a number of years, Goldkamp (2004, also Goldkamp et al, 2001) has identified the three critical components of Drug Courts to be the treatment provided to participants, the appropriate use of sanctions and judicial involvement. In particular, he found that higher levels of contact with the same judge resulted in lower levels of recidivism. Other commentators have also highlighted the central role played by sentencers in the Drug Court process (for example, Wager, 2002). A recent review of specialist courts in different jurisdictions commissioned by the Department of Constitutional Affairs for England and Wales concluded that among the key features of these courts associated with success was:

“A flexible judicial attitude with a willingness to experiment with new 'team' approaches to diverting offenders from criminality; participate in the on-going monitoring of offender behaviour; and communicate to others the benefits of the work they do" (Plotnikoff and Woolfson, 2005, p.64)

In Scotland, as in other jurisdictions, the vehicle for ongoing contact between sentencers and participants is the regular court-based review. Although reviews are now accepted as an integral feature of the pilot Drug Courts and DTTOs (and also feature in the pilot youth Courts that were established in 2003 and 2004), judicial involvement in sentence oversight and management is a relatively novel concept in Scotland as, indeed, it is elsewhere. Previously, although they would receive 
completion reports on all offenders made subject to probation orders, sentencers would only have further face-to-face contact with those who breached community based disposals and were returned to court for re-sentencing.

Although the Scottish Drug Court Sheriffs were not operating explicitly within a model of therapeutic jurisprudence (Wexler and Winick, 1992), it is clear that a central concern was in creating the conditions through which the Drug Court process could encourage and support participants in their efforts to reform. In this respect, rehabilitation was regarded as a fundamental objective of the Drug Courts that the Sheriffs, according to both professionals and offenders alike, had a crucial role to play in achieving.

\section{Pre-review meetings}

Before offenders appeared in the Drug Courts to have their orders reviewed, prereview Drug Court team meetings were convened in the morning to enable multiprofessional discussion of the progress of individual participants. Although convened in the courtrooms, they were relatively informal in nature, being characterised by open sharing of information and discussion. Sheriffs valued having the opportunity to obtain feedback from those directly involved in supervising and treating the offender and regarded these meetings as an invaluable information-gathering forum for providing "an overall picture" of each participant.

On a purely practical basis, the pre-review meetings meant that Sheriffs were furnished with information from social workers, addiction workers and medical staff 
that was up-to-date (rather than based on a report that had been prepared several days previously), they allowed for additional information to be gathered where further clarification of an issue was required prior to the review and they enabled consideration to be given to sensitive issues (such as health or domestic matters) that it would be inappropriate to discuss in open court. From a therapeutic jurisprudential perspective, the information gleaned at the pre-review meetings was important to Sheriffs in deciding "which buttons to push" in their subsequent dialogue with a participant: whether there were particular achievements to acknowledge or, conversely, whether there were setbacks that needed to be commented upon and addressed. Another important function of the pre-review meetings was to enable the Sheriff to "choreograph" the subsequent hearings to amplify the message s/he wanted to convey by arranging the court schedule in such a way that participants who were present in court could witness and benefit from the Sheriff's response to previous participants. For example, a participant who was experiencing a setback in the midst of otherwise steady progress might be scheduled to appear immediately following another who had similarly experienced such a setback that had been successfully resolved. The ability to discuss cases in depth in a multi-professional forum and to organise subsequent review hearings based on such detailed knowledge of cases would clearly not have been possible if the Drug Court caseloads had grown significantly: had they done so the Drug Courts may have been required to sit on additional days to maintain the quality of preparation and review.

\section{Review hearings}


In both Drug Courts review hearings were held in open court in the afternoon. Participants and family members awaited their scheduled hearing in the spectator seating area or in the corridors. While family members were often not present, their attendance at court was regarded by professionals as important since it provided them with an opportunity to witness the progress the participant was making and how it was being recognised and acknowledged by the court. As one Sheriff commented:

\footnotetext{
“They've turned up with their families to see that they're doing well because they've probably not done anything particularly worthwhile in their family's eyes for a long time."
}

Offenders similarly alluded to the significance of Drug Court reviews being conducted in public as a means of demonstrating their progress to other participants, family members and friends. One participant, for example, described the primary purpose of the Drug Court as being:

"To let the judge and let the parents, let my mum and dad - they come up - to let them see that I'm not lying to them, that my urines are negative or they are positive. So it helps build up a wee bit of trust in the house."

Drug Court participants at different stages of their orders generally viewed review hearings in positive terms, regarding them as a forum in which progress and compliance was assessed, through which their problems and needs could be identified and addressed and through which they could receive verbal reinforcement for their 
efforts. In this sense, reviews were regarded by participants in broadly therapeutic terms:

"Just to see where you are on the order and what you are doing to fill your time. Also if you have a problem, so the court can have a look at you and make sure you are OK."

"To monitor how you're doing on the order and change it to suit your needs."

"The purpose of the court review is to give you that wee boost, that wee initiative. To give you praise, tell you that you're doing well, keep up the good work."

"You could say it's like building up a relationship with the Sheriff."

That said, some participants also alluded to the deterrent function of reviews, though this was not necessarily perceived in overtly punitive terms. Having to attend reviews helped to keep participants 'on their toes' and served as a deterrent to continued drug use and offending. Although the imposition of a custodial sentence was recognised as an ever-present possibility in the face of non-compliance, the willingness of the court to support people during setbacks and to give them another chance was often stressed. 
Unlike in traditional courts, where the majority of dialogue in the Drug Courts is conducted between the Sheriff and the defence agent, most of the review hearings involved direct communication between the participant and the bench. As one participant explained, a key difference between the Drug Court and an ordinary court was that "it seems everything's directed to me, myself, instead of my lawyer". Being addressed directly by the Sheriff was initially unnerving for many participants, who were not accustomed to being engaged in dialogue with sentencers:

“The first couple of reviews I didn't like. I felt awkward, you know, just not being used to it...I'm getting more and more comfortable as each review goes on."

“Intimidating really, because I'm used to just going in and getting a sentence from the judges. Him talking to us the way he talks to us is totally different. At first I was scared to say anything. Now it's a wee bit different. Every time I went in he has praised me - said how well I'd done... Now I can talk back to him just a wee bit"

"I think that as time goes on you get a bit more confident with the judge and start to speak to him for a bit longer. You feel more confident because they listen to you."

Observation of the Drug Courts in action confirmed that exchanges tended to become longer as orders progressed and participants felt more comfortable discussing their progress and circumstances with a Sheriff. As one Sheriff observed: 
"I've tried when I'm imposing an order in the Drug Court to have their input immediately in it. They're usually quite reticent - they mumble something about wanting to change and so forth. As the thing progresses they get more confident - they do give you an element of feedback."

Professionals and respondents alike attached considerable significance to the regular review hearings. Sheriffs in particular regarded them as the vehicle for bringing together the legal and therapeutic aspects of the Drug Court. While the court setting served to underscore the formality of the process, conducting reviews enabled sentencers to take cognisance of the individual's response to supervision and treatment and, as appropriate, to motivate, sanction and enforce. Reviews, according to one Sheriff, represented the point where "the legal side of things melds with the non-legal, sort of therapeutic side of things". As "the process which joins the two together", reviews could be conceptualised as "the nexus between the two aspects of the approach".

\section{The content of reviews}

Turning to the content of reviews, it was apparent that most comments made by the Sheriffs were encouraging, aimed at recognising and reinforcing the progress made by participants and motivating then to maintain and build upon their achievements to date. This included comments such as "you've made remarkable progress indeed!" 
and "this is a very good start and I will be pleased to see the same next month. Work on your opiate use and try to get some negatives".

Particularly in later reviews, once participants had been in treatment for some time and had stopped using street drugs, Sheriffs often remarked upon improvements in their physical appearance, by making comments such as "you look better every time" and "you're looking better than expected".

Despite their initial reticence, participants were generally responsive to the positive feedback they received from the Sheriffs as their orders progressed. Comments such as "I'm brilliant - the best I've been for along while" and "I'm feeling good, I'm doing well. I've never had this challenge before" were typical.

However, Sheriffs also played an important role in enforcing orders and sanctioning those who had failed to comply (for example, through further drug misuse or for failing to keep appointments with social workers, addiction workers or medical staff). In these circumstances, Sheriffs often emphasised the potential consequences of continued transgressions:

"It's for your benefit. At the end of the day, I walk out of the court and you may not. I want to see you back on the rails: please, please co-operate over the next two weeks to make some kind of progress!"

"This is serious! You are up on indictment and many of my colleagues would have jailed you. I will take serious steps if you don't comply." 
In these circumstances participants often expressed some contrition and emphasised their renewed resolve, through comments such as "give me another chance m'lord" and "I want another bite of the cherry".

As previously indicated, relapse was recognised by the Sheriffs and by other professionals as a common feature of participants' efforts to become drug free. Resorting to further drug use, while not condoned, was responded to sympathetically if participants had previously been making determined efforts to change. As one Sheriff observed, "I don't expect miracles from you but do try and keep it up. It shows you what can happen if you drop your guard" and another observed: "You're making efforts. You are trying and there are difficulties".

The earlier evaluation of DTTOs in Scotland (Eley et al, 2002) had shown that a high risk period for relapse was around 4-6 months into an order once offenders were stabilised on or reducing their methadone and had had a run of negative tests. At this stage, offenders tended to become complacent about the risk of further drug use and consequently made less conscious effort to avoid situations or places in which temptation might be present. Sheriffs recognised this risk of complacency and emphasised the importance of participants remaining alert to such pressures once they had started to produce clear drug tests with comments such as "you'll find temptations put your way but try and avoid them" and "you've got to keep it up - times will get harder".

\section{The significance of dialogue in reviews}


What the previous excerpts from Drug Court dialogues convey, among other things, is the interest and concern expressed by sentencers, on the one hand, and the responsiveness of the offenders to the Sheriffs' exhortations and advice on the other. These dialogues helped to forge the type of relationship between sentencers and offenders that would not be possible within a traditional adversarial court setting. As one Sheriff explained:

"In the Drug Court you have more of a personal connection with the individual in the sense that you interrelate to them directly and speak to them directly more often that you would in an ordinary court."

The sharp contrast between Drug Court dialogues and the brief and rather stilted exchanges between Sheriffs and offenders that typically took place in other courts was widely alluded to by other professionals associated with the Drug Courts. As one professional respondent observed:

"I think it's remarkable, I think the Sheriff actually talks to the offender in a normal everyday language. There may be, you know, cultural differences, but in everyday language with them. It's a major step forward in legal history I would have thought. It won't be viewed as that at the moment but in the years to come I'm sure it will."

Engaging with offenders and encouraging them to discuss their progress and setbacks was regarded by Sheriffs as means of enhancing participants' commitment and 
motivation to change by involving them and giving them an increased sense of personal agency:

"It's important I think from the point of view of the accused that he is a real part of the process - rather than just a product he has an investment in it and he wants to appreciate that he himself will influence what happens to him."

Drug court participants clearly attached considerable significance to the dialogue that took place between them and the Drug Court Sheriffs. Many participants indicated that the Sheriff was someone they could discuss their problems with in confidence (albeit in open court) and whom they trusted to provide assistance they required.

\footnotetext{
"In a court room you like to hide a few of your feelings and in there you can just tell them what you think knowing you are not going to get criticised for speaking out."
}

Some participants alluded directly to the relationship they established with the Sheriff through the ongoing court-based exchanges. The Sheriffs helped them to relax and open up and engendered trust. An important feature was the fostering of equality and reciprocity in the discussions that took place which contrasts with the strict hierarchical relationships and imbalances of power that usually typify such exchanges in court: 
"It gives a chance for you to build up a sort of relationship with him where the two of you can speak to each other on equal terms, rather than sort of looking up at him and saying 'that guy's got my fate in his hands"."

"He basically says you can talk to him the way you speak to anybody of course you have got to speak to him polite - but man to man basically, kind of thing. So you can tell him if things are not working out and he will look at it. My Sheriff does anyway."

Many participants emphasised the difference between the Drug Court Sheriffs and sentencers that they had previously encountered in other courts, with the Drug Court Sheriffs invariably emerging positively from such comparisons. The 'otherness' of the Drug Courts Sheriffs was lessened and they were 'humanised' in comparison with other sentencers. The key (positively) distinguishing attributes that participants identified in the Drug Court Sheriffs were their willingness to listen and understand, their discretion, insight and tact and their knowledge of issues affecting drug users:

"You don't think you're important enough to speak to a Sheriff. Cos you open your mouth maybe in court and go 'that's not right', they would just go 'silence' do you know what I mean? But in there if you were to say 'that's not right Sheriff', I don't know why that is, they'll listen and they make you feel important and you actually go out of the court on a high." 
"I like talking to him because he does listen to you. He knows about my sexual abuse and that. He'll not mention it in open court, but he'll say more or less 'there are other issues here - I can see that you've been trying to deal with them'."

“[Drug Court Sheriff]is a really nice Sheriff. I'm sure you've heard him. He'll listen to your point of view and there's not many Sheriffs that will. He looks through the addiction, I think, and sees the person who is there."

"He's a figure of authority but he doesn't come across as a Sheriff, you know, somebody that's there to decide your fate and he'll send you to gaol. He's friendly, you know, he's a compassionate man, he's very friendly...He seems to be the type of person that's interested. He's got a great passion for what he's doing."

When discussing their experiences of reviews, participants frequently referred to 'their' Sheriff. It was clear that continuity of sentencer over successive reviews was important to participants. Most participants had the same Sheriff conduct all of their review hearings. This was regarded as a necessary precondition for a productive relationship with the bench and was viewed positively because it signified that the sentencer dealing with them was familiar to them and well-informed about their case. Those participants who had appeared before another Sheriff expressed concern that the other Sheriff knew less about their circumstances and were less able to understand their current situation in relation to their previous experiences on the order. 
"It's good because he knows everything that happened in the last review. If it was a good review and then everything sort of went downhill a bit and you got a different judge he wouldn't sort of know you. So it's better having the same judge."

\section{Why does judicial involvement matter?}

The preceding exploration of judicial involvement in the Scottish Drug Courts highlights how, even if not explicitly so, sentencers were adopting approaches and practices consistent with therapeutic jurisprudence (Wexler and Winick, 1992). In particular, interactions between offenders and the bench were characterised by meaningful exchanges aimed at supporting and encouraging offenders in the process of change within a climate of trust and an 'ethic of care' (Winick and Wexler, 2003). Winick and Wexler (2003, p.17) have argued that "relationships and processes are more important than the substance of therapies and sanctions" while Wexler (2001) has suggested that judicial involvement can promote rehabilitation by contributing to the 'desistance narratives' (Maruna, 2001) that help to bring about and sustain desistance from crime. Drug Court dialogues may also serve to underscore the significance of sentencing (Duff, 2001). Although the limited scale and timescale of the Scottish Drug Court evaluation did not allow for the contribution of various strands of the process to be identified, Goldkamp's (2004) analysis suggests that the Drug Court sentencers may have a direct influence upon participants' responses to treatment and desistance from crime. 
Therapeutic jurisprudence is an approach or set of organising principles rather than a theoretical perspective and as such lacks explanatory power. However, Tyler's (1990) research on procedural justice and legitimacy provides a theoretical rationale for why the approaches taken by sentencers in the Drug Courts might contribute to improved outcomes for participants. Based an a panel study of attitudes towards and experiences of judicial processing, Tyler found that if people perceived themselves to be treated fairly, they were more likely to view judges as having legitimacy and the greater the perceived legitimacy of judges, the greater the level of compliance with their demands. He further contends that procedural justice "is the key normative judgement influencing the impact of experience on legitimacy" (p.162). The actual decisions reached by judges are held to be less important than the opportunity for individuals to state their case and be heard, and being listened to by the authorities can enhance self-esteem. This, in turn, can enhance intrinsic motivation to change as opposed to the extrinsic motivation that derives from punishment and deterrence and which dispels when the threat of punishment is removed. As Tyler and Huo (2002, p.205) have argued, "to the extent that people have willingly accepted authorities' decisions, their motivation to continue abiding by these decisions in the future is greater".

Tyler (1990) identifies a number of factors that enhance the sense of procedural justice. In the court setting these include ethicality, quality of decisions, efforts to be fair, correctability, honesty, representation and lack of bias. In the Scottish Drug Courts, three factors in particular (though not exclusively) were plainly in evidence. 


\section{Ethicality}

Tyler defines ethicality as being demonstrated through politeness, respect and a demonstration of concern for individuals' rights. This was manifested in the Drug Courts through the praise and encouragement offered by Sheriffs and through the respectful manner in which participants were treated. Tyler (1990) argues that ethicality enhances self-respect which, in turn, is linked to overall well-being:

\footnotetext{
"It gives you a wee boost...saying to you he's proud, 'I'm glad you have done this and done that' and it gives you a wee boost when you go home from court."
}

"You feel good cos you just spoke directly to the Sheriff. And he treats you with the utmost respect as you seen in the court for yourself. And he'll praise you but if you're doing bad he'll kick your arse really severe."

“...what's good about it is because I'm getting treated now like a human being and an equal..."

\section{Effort to be fair}

Procedural justice is also enhanced when the sentencer is perceived to have made an effort to be fair. This was demonstrated in the Scottish Drug Courts through the interest shown by Sheriffs in the progress and well-being of participants and through 
their willingness to make appropriate allowances when offenders experienced setback on their orders. As one participant explained "these people actually want to give you a chance", while another observed:

"I think he's really fair and he gives you a chance to like, express your feelings, and just to tell him how you've been doing every month. And I just feel he is really fair, I mean he likes to take an interest basically to see how you're doing and that."

As Tyler (1990) contends, feeling that Sheriffs had made strenuous efforts to help them to remain on their orders and remain in treatment appeared to be more important to participants than any sanctions that might be imposed as a result of individual of sustained instances of non-compliance: in other words, the process was more important than the outcome and adverse outcomes were accepted by participants if they felt that they had been treated fairly. Throughout their orders most participants indicated that the approach taken by Sheriffs was fair and honest and took account of difficulties they had experienced. It was rare for participants to be critical of Sheriffs. Rather, they emphasised how they had always had an opportunity to state their point and that the consequences of continuing to indulge in prohibited behaviours had been made perfectly clear from the outset. Most of those who breached their orders and had them revoked acknowledged their contribution to this outcome. While a few believed they had been treated harshly by the sentence they received, more often participants felt that the disposal they received was warranted and took account of their problems and the progress they had made. 
"He obviously understood why everything went pear-shaped and he was very lenient with me... He was good to me and tried to help me. I could never complain about him - never."

"I got 12 months custody...I think it was a fair sentence and it took the improvements and the problems I'd had and all that into account."

\section{Representation}

Tyler (1990, p.126) has argued that "when respondents react to their experiences with legal authorities, they focus more on the opportunities to state their case than they do on their influence over decisions". The third aspect of procedural justice that was particularly prominent in the Drug Courts was representation - the opportunity for participants to give an account of their progress and to offer explanations if things were not going well. As one participant explained, "I think it's quite a good idea - you can put your views across, good or bad he listens to you."

Tyler (p.150) has also suggested that "the elements of interaction with the authorities that enhance self-esteem depend on the belief that the authorities are paying attention to what the citizen is saying. Self-esteem is not enhanced by being ignored" Professionals associated with the Drug Court were alert to the significance of the court listening to participants and allowing them to have their say, particularly given their lack of voice and powerlessness in most encounters with legal and other authorities. As one Sheriff explained: 
"This is the first time probably in their lives that anybody of any sort of authority has listened to what they had to say and I think it's important that they're treated like human beings."

The fact that participants were listened to and therefore had some control over the process was also regarded as important by professionals because it meant that participants were ascribed personal agency and, as a consequence, were more likely to become committed to making and sustaining changes in their lives. As one Sheriff commented:

"I think it's about giving the person a voice. It makes them part of the whole process, you know, they're not being talked at. This is not something that is being done to them - they are part of it and they have a say in what's happening."

\section{Conclusions}

Drug Courts are complex enterprises, involving elements of supervision, treatment, drug testing, review and enforcement, entailing the co-operation of a range of criminal justice, health and social work professionals and requiring effective links to be made with a range of community-based agencies that can facilitate participants' successful re-integration into the community during the currency of their orders and beyond. Each of these elements is likely to contribute in some way to the effectiveness of Drug Courts in bringing about individual change. For example, without accessing treatment, it is very unlikely that offenders would stop using drugs. Drug testing while 
in treatment can serve both as a deterrent to further drug use and an incentive to maintaining progress that has been made. Sanctions and rewards can similarly serve as a carrot and stick, acknowledging and reinforcing progress and addressing setbacks and lack of compliance. Access to other services is also likely to be important to provide offenders with opportunities for re-integration into their communities in the longer term. Effective team work is also essential in order that participants receive consistent messages and so that a co-ordinated approach to their circumstances and problems is achieved.

This article has focused on one element that of the Drug Court process: judicial involvement on the management of Drug Court participants and, in particular, the nature of the interaction between sentencer and offender that takes place in that context. The resulting data suggest that the interactions that took place in court between offenders and sentences encouraged increased compliance and supported offenders in their efforts to address their drug use and associated offending. However, it also needs to be recognised that there are a number of factors that may have impacted upon the quality of Drug Court interactions.

First, during the first two years of the Glasgow pilot, most offenders who entered the Drug Court had tendered early guilty pleas and might be assumed, therefore, to have been relatively motivated at the outset to engage with a Drug Court regime. The referral routes into the Glasgow Drug Court were subsequently broadened to increase the level of referrals and this had the effect of bringing into the Drug Court increasing proportions of offenders who pled or were found guilty later in the trial process. Whether this change in the pattern of direct referrals from other Sheriffs (from $8 \%$ in 
the first two years to 52\% in the third year (McIvor et al., 2006)) has had any bearing in the longer term upon the nature of in-court interactions remains to be seen, though observation of the Glasgow Drug Court in the third year did not yield any immediate indications that this had altered.

A second relevant consideration is the extent to which Drug Court processes might be affected by changes in personnel. In particular, the Drug Court Sheriffs had volunteered in sit in the Drug Courts and brought to their role a degree of enthusiasm and commitment (enhanced by further training in relation to drug misuse and treatment) that might not have been evident among other members of the bench. For example, when DTTOs were rolled out across Scotland they received a mixed reception among the judiciary. Some grasped the new sentencing option enthusiastically while others, if not explicitly hostile to the concept of ongoing offender review, were much more muted in their response, and this has been reflected in wide geographical variations in the use of orders (Scottish Executive, 2007). It is possible, therefore, that the success of the Drug Courts in engaging and motivating offenders was dependent to a large extent on the attitudes and approaches of the original sheriffs, whose interest is the Drug Court had developed from their earlier experience of making DTTOs. In Glasgow the two original Sheriffs were replaced, in a phased manner, with two new Drug Court Sheriffs at the beginning of the third year of the pilot. Given the apparent centrality of the sentencer to the Drug Court process, this change might have been expected to impact on how the court operated. Although the Sheriffs differed from one another in terms of the specifics of their approach, the change in personnel appeared to have little discernible impact on the court's operation and continuity of approach was, generally speaking, maintained. This might be 
attributable to the strong emphasis upon inter-professional teamwork in the Drug Courts, aimed at fostering a common understanding of and approach towards drug misuse and drug-related crime.

A third issue to consider is the relevance of gender, both of the sentencer and of the offender, to the nature and dynamics of court-based exchanges. Female offenders were vastly outnumbered by men on Drug Court Orders (91\% of cases in Glasgow and $84 \%$ in Fife) and other than in the third year of the Glasgow pilot, all of the Drug Court Sheriffs were male (McIvor et al., 2006). The low number of women on Drug Court Orders was reflected in their under-representation in reviews of court proceedings and research interviews and all of the offenders quoted in this article were men. Women were found, however, to have lower completion rates than men in both pilot sites (McIvor et al., 2006) and, while Sheriffs tended to attribute this to the adverse influence of female participants' drug-using partners, it is possible that Drug Court interactions may have been less effective in engaging women and helping to sustain their motivation to change. Future research might, therefore, usefully focus on the relevance of gender for the nature and effectiveness of court-based reviews.

The contribution of judicial oversight and review to the outcomes for offenders who participate in them could not be quantified and the preceding limitations need to be acknowledged. However it appeared that for some participants in the Scottish Drug Courts, interaction with the Sheriff was central to their achieving and sustaining positive change: 
“Now, it's in the back of my head 'don't take that' [referring to drugs] because the judge ... gave me a chance, he'll not take it. At least he is giving me a chance to help me. He knows the score and in my head I'm not wanting to mess him about. In my opinion it was him that really helped me."

A recent quantitative analysis of the experiences of participants in the Baltimore City Drug Treatment Court found that judicial review directly reduced drug use and indirectly reduced criminal behaviour by increasing participants' perceptions of procedural farness (Gottfredson et al., 2007). Similarly, a process evaluation of the pilot Drug Courts in England found that continuity of sentencer across court appearances was associated with enhanced compliance with court hearings, lower levels of positive drug tests for heroin, an increased rate of completion of orders and a reduced frequency of reconviction (Matrix Knowledge Group, 2008). By drawing upon the views and experiences of Scottish Drug Court participants and professionals and through analysis of interactions in court, it is argued that the exchanges that take place between sentencers and offenders can be a critical element in encouraging compliance both during an order and in the longer term. Elements of procedural justice were clearly manifested in the Scottish Drug Courts and this, according to Tyler (1990) is likely to confer greater legitimacy to sentencers and to increase the responsiveness of participants to their exhortations that they should change.

\section{Notes}


1. A subsequent analysis of recidivism suggested that the rate and frequency of reconviction was lower in the two years following a DTTO than in the two years immediately before (McIvor, 2004). However, in the absence of a comparison group it is difficult to determine to what extent this improvement in offending would have occurred anyway, even if offenders had not been given DTTOs.

2. Interest in problem-solving courts was consistent with a greater policy emphasis in Scotland than in other parts of the UK on offender rehabilitation (in the wider sense of the term) and the promotion of social inclusion.

3. The legislation does not allow for DTTOs to be reviewed more often than monthly. Probation orders can be reviewed as often as the court decides, though in practice the in-court review of orders is uncommon outwith specialist courts.

4. For example, an outstanding offence might be dealt with by means of an admonishment if the offender was progressing well.

5. This might include the imposition of a short custodial sentence (for example, for 7 or 14 days) while allowing the main Drug Court disposal (DTTO or probation order) to continue.

6. Offenders were almost always bailed for assessment rather than remanded in custody since voluntary attendance at several appointments for testing and assessment was regarded as an indicator of the offender's motivation to participate in a Drug Court programme.

7. The most common duration for orders in the first two years was 18 months. 8. The original two Sheriffs were replaced by two new Sheriffs in 2004.

\section{References}


Bean, P. (2002) Drugs and Crime. Cullompton: Willan Publishing.

Belenko, S. (1998) Research on Drug Courts: A Critical Review. New York: The National Center on Addiction and Substance Abuse at Columbia University.

Belenko, S. (2001) Research on Drug Courts: A Critical Review 2000 Update. New York: The National Center on Addiction and Substance Abuse at Columbia University.

Duff. R. A. (2001) Punishment, Communication and Community. Oxford: Oxford University Press.

Eley, S., Gallop, K., McIvor, G., Morgan, K. and Yates, R. (2002) Drug Treatment and Testing Orders: Evaluation of The Scottish Pilots. Edinburgh: Scottish Executive Social Research.

Eley, S., Malloch, M., McIvor, G., Yates, R. and Brown, A. (2002) Glasgow's Pilot Drug Court in Action: The First Six Months. Edinburgh: Scottish Executive Social Research.

Freeman, K. (2002) New South Wales Drug Court Evaluation: Health, Well-being and Participant Satisfaction. Sydney: New South Wales Bureau of Crime Statistics and Research. 
Gebelein, R.S. (2000) The Rebirth of Rehabilitation: Promise and Perils of Drug Courts, Sentencing and Corrections: Issues for the $21^{\text {st }}$ Century. Washington D.C.: NIJ.

Goldkamp, J.S. (2000) What do we know about the impact of Drug Courts: Moving research from 'Do they work?' to 'When and how they work', Testimony to the Senate Judiciary Committee on Youth Violence. Philadelphia PA: Crime and Justice Research Institute.

Goldkamp. J.S., White, M.D. and Robinson, J.B. (2001) From Whether to How Drug Courts Work: Retrospective Evaluation of Drug Courts in Clark County (Las Vegas) and Multnomah County (Portland). Philadelphia, PA: Crime and Justice Research Institute.

Goldkamp, J.S. (2004) Judicial 'Hands On' in Drug Courts: Moving from Whether to How Drug Courts Work. Paper presented at the 1st Key Issues Conference of the International Societies of Criminology, Paris.

Gottfedson, D.C., Kearley, B.W., Najaka, S.S. and Rocha, C.M. (2007) 'How Drug Treatment Courts work: An analysis of mediators', Journal of Research in Crime and Delinquency 44 (1): 3-35.

Hough, M. (1996) Drug Misuse and the Criminal Justice System: A Review of the Literature. London: Home Office. 
Hough, M., Clancy, A., McSweeney, T. and Turnbull, P. (2003) The Impact of Drug Treatment and Testing Orders on Offending: Two-year Reconviction Re s u l t s, HORSD Findings 184. London: Home Office.

Indermaur, D, Roberts, L, Morgan, N \& Valuri, G (2004) Evaluation of the Perth Drug Court Pilot Project. Perth, WA: West Australian Department of Justice.

Lind, B., Wratherburn, D., Chen. S., Shanahan, M., Lancsar, E., Haas, M. and De Abreu Lourenco, R. (2002) New South Wales Drug Court Evaluation: CostEffectiveness. Sydney, NSW: New South Wales Bureau of Crime Statistics and Research.

Makkai, T. and Veraar, K. (2003) Final Report on the South East Queensland Drug Court: Australian Institute of Criminology Technical and Background Paper Series No. 6. Canberra, ACT: Australian Institute of Criminology.

Malloch, M., Eley, S., McIvor, G., Beaton, K. and Yates, R. (2003) The Fife Drug Court in Action: The First Six Months. Edinburgh: Scottish Executive Social Research.

Maruna, S. (2001) Making Good: How Ex-inmates Reform and Rebuild their Lives. Washington DC: American Psychological Association.

Matrix Knowledge Group (2008) Dedicated Drug Court Pilots: A Process Report. London: Ministry of Justice. 
McIvor, G. (2004) Reconviction Following Drug treatment and Testing Orders.

Edinburgh: Scottish Executive Social Research,

http://www.scotland.gov.uk/Resource/Doc/26350/0029550.pdf

McIvor, G., Barnsdale, L. Malloch, M., Eley, S. and Yates, R. (2006) The Operation and Effectiveness of the Scottish Drug Court Pilots. Edinburgh: Scottish Executive Social Research, http://www.scotland.gov.uk/Resource/Doc/100021/0024203.pdf

McSweeney, T., Stevens, A., Hunt, N. and Turnbull, P. (2006) The Quasi-compulsory Treatment of Drug-dependent Offenders in Europe: UK Findings, http://www.kent.ac.uk/eiss/publications/UK\%20QCT\%20Findings.pdf

McSweeney, T., Stevens, A., Hunt, N. and Turnbull, P. (2007) Twisting arms or a helping hand? Assessing the impact of 'coerced' and comparable 'voluntary' drug treatment options, British Journal of Criminology 47 (3): 470-90.

Plotnikoff, J. and Woolfson, R. (2005) Review of the Effectiveness of Specialist Courts in Other Jurisdictions. London: Department of Constitutional Affairs.

Reid-Howie Associates (2007) Evaluation of the Pilot Domestic Abuse Court.

Edinburgh: Scottish Executive Justice Department, http://www.scotland.gov.uk/Resource/Doc/173485/0048418.pdf

Scottish Executive (2005) Costs, Sentencing Profiles and the Criminal Justice System 2003: Section 306, Edinburgh: Scottish Executive. 
Scottish Executive (2007) Criminal Justice Social Work Statistics 2005-6, Edinburgh: Scottish Executive.

Taplin, S. (2002) The New South Wales Drug Court Evaluation: A Process

Evaluation. Sydney, NSW: New South Wales Bureau of Crime Statistics and Research.

Tyler, T. (1990) Why People Obey the Law. New Haven CT: Yale University Press.

Tyler, T. and Huo, Y.T. (2002) Trust in the Law: Encouraging Public Co-operation with the Police and Courts. New York: Russell Sage Foundation.

Turnbull, P.J., McSweeney, T., Webster, R., Edmunds, M. and Hough, M. (2000) Drug Treatment and Testing Orders: Final Evaluation Report. Home Office Research Study 212, London: Home Office.

Wager, J. (2002) The Drug Court: Can a relationship between health and justice really work?. Paper presented at Alcohol and Other Drugs: Collaborating for Better Care, Inaugural Alcohol and Other Drug Symposium, Fremantle, WA.

Walker, J. (2001) International Experience of Drug Courts. Edinburgh: Scottish Executive Central Research Unit. 
Wexler, D.B (2001) 'Robes and rehabilitation: How judges can help offenders 'make good', Court Review Spring: 18-23.

Wexler, D.B. and Winick, B.J. (1992) 'The potential of therapeutic jurisprudence: A new approach to psychology and the law', in J.R.P. Ogloff (Ed.) The Law and Psychology: The Broadening of the Discipline. Durham, N.C: Carolina Academic Press.

Winick, B. J. and Wexler, D. B. (2003) Judging in a Therapeutic Key. Durham, NC: Carolina Academic Press.

Wilson, D.B., Mitchell, O. and MacKenzie, D.L. (2004) A Systematic Review of Drug Court Effects on Recidivism. Paper presented at the 1st Key Issues Conference of the International Societies of Criminology, Paris. 